\title{
FERTILIZAÇÃO E QUALIDADE DA ÁGUA DE IRRIGAÇÃO NO CRESCIMENTO E DESENVOLVIMENTO DA ALFACE
}

\section{INFLUENCE OF FERTILIZATION AND QUALITY OF WATER IRRIGATION ON GROWTH AND DEVELOPMENT OF LETTUCE PLANTS}

\author{
João Antônio GALBIATTI' \\ Ítalo Herbert Lucena CAVALCANTE ${ }^{2,4}$ \\ Adriano Gerim RIBEIRO ${ }^{3}$ \\ Márkilla Zunete BECKMANN-CAVALCANTE ${ }^{4}$
}

\begin{abstract}
RESUMO
O presente trabalho foi desenvolvido no CEA/UNESP, com o objetivo de avaliar os efeitos das diferentes fontes de adubação e da qualidade da água de irrigação no crescimento e desenvolvimento da cultura da alface. Adotou-se delineamento em blocos casualizados, com tratamentos distribuídos em esquema fatorial $5 \times 2$, correspondentes aos tipos de fertilização (não adubado, efluente de biodigestor, esterco bovino, cama-de-frango, adubação mineral) e qualidades de água de irrigação (tratada e residuária), com três repetições. Foram avaliados os parâmetros altura de planta, diâmetro do caule, produção de matéria seca e fresca e índice de área foliar. Apenas houve influência estatística dos tratamentos na produção de matéria seca e fresca, com inferioridade dos tratamentos não adubados. Não houve diferença no crescimento da alface quando submetido às diferentes fontes de fertilizantes. A qualidade da água não exerceu influência sobre o crescimento e desenvolvimento da alface.

Palavras-chave : Lactuca sativa, adubação orgânica, qualidade de produção.
\end{abstract}

1Prof. Dr, Depto. Engenharia Rural, UNESP-FCAV. E-mail: galbi@fcav.unesp.br

${ }^{2}$ Prof. M.Sc, Universidade Federal do Piauí, Campus Prof a Cinobelina Elvas, BR-135. km-3, Bom Jesus, Piauí. Doutorando FCAV/UNESP. *Autor correspondente.E-mail: italohlc@ufpi.br

${ }^{3} \mathrm{MSc}$. Centro de Estudos Ambientais, UNESP-CEA, Rio Claro (SP). E-mail: adriano.ribeiro@alcoa.com.br

${ }^{4}$ DSc. Depto. Horticultura, FCAV-UNESP. E-mail:zunete@fcav.unesp.br 
GALBIATTI, J. A. et al. Fertilização e qualidade...

\section{INTRODUÇÃO}

Durante a última década, o nível de conscientização quanto às relações da agricultura com o meio ambiente, os recursos naturais e a qualidade dos alimentos cresceu substancialmente. À medida que a população e as atividades econômicas crescem, muitos países estão se defrontando com limites para o desenvolvimento econômico, seja do ponto de vista de salinização dos solos pelo excesso no fornecimento de fertilizantes químicos, seja atingindo rapidamente condições de escassez de água sem restrições para o uso agrícola (BRASIL, 2005).

A qualidade da água para a agricultura é determinada sob enfoques de pureza, microbiológicos e químicos, este último determinado pela concentração e composição dos sais constituintes dissolvidos. Os efeitos nocivos das águas de qualidade limitada no sistema solo-planta têm sido verificados na prática e podem interferir significativamente nos atributos edáficos e no desempenho produtivo das culturas (CAVALCANTE, 2000).

A incorporação de resíduos orgânicos no solo tem as finalidades de aumentar a capacidade de retenção de água, fornecer nutrientes, formar um ambiente propício à atividade microbiana e influenciar positivamente na aeração do sistema poroso, proporcionando um equilíbrio dinâmico do sistema solo-planta-atmosfera (KIEHL, 1985). Entretanto, a pureza do material a ser empregado em relação à contaminação por coliformes fecais e a possibilidade de transformação do nitrogênio em nitrato, passando a constituir um contaminante de águas subterrâneas e de superfície são tópicos bastante estudados em países desenvolvidos. No Brasil já se podem encontrar áreas contaminadas devido à utilização de águas residuárias sem estudo quantitativo e qualitativo prévio.

A alface (Lactuca sativa L.) é uma hortaliça folhosa que possui cerca de 75 cultivares comerciais, dentre as quais 18 foram obtidas no Brasil, onde apresenta o maior valor comercial dentre as demais folhosas (FILGUEIRA, 2000).

O fornecimento de adubação orgânica a partir de esterco animal e compostos orgânicos tem sido uma prática adotada com a finalidade de reduzir a utilização de fertilizantes químicos e melhorar as características físicas e químicas dos solos.

O presente trabalho teve por objetivo estudar os efeitos das diferentes fontes de fertilizantes e a qualidade da água de irrigação no crescimento e desenvolvimento da cultura da alface.

\section{MATERIAL E MÉTODOS}

Os experimentos foram conduzidos em casa-de-vegetação do tipo arco conjugado, coberto com filme plástico de polietileno no Centro de Estudos Ambientais (CEA), Universidade Estadual Paulista, Rio Claro, SP. Três cultivos da alface (Lactuca sativa L.) foram realizados, o primeiro no inverno (21/05/2004-26/06/2004, 37 dias), o segundo na primavera (09/08/2004-16/09/2004, 38 dias), e o terceiro no verão (27/11/2004-08/01/2004, 43 dias), a variedade de alface utilizada foi a "Verônica", comercialmente cultivada na região.

A semeadura ocorreu em bandejas de poliestireno expandido em 05/05/2004 (ciclo 1), 22/ 07/2004 (ciclo 2) e 12/11/2004 (ciclo 3) e as mudas homogêneas foram transplantadas aproximadamente 15 dias após. O plantio foi feito com espaçamento $25 \mathrm{~cm}$ entre linhas e $20 \mathrm{~cm}$ entre plantas, em caixas de amianto (30 no total) com volume aproximado de $0,5 \mathrm{~m}^{3}$ e área superficial de $1 \mathrm{~m}^{2}$, assentadas sobre base de blocos de cimento preenchidas com Latossolo Vermelho Amarelo Distrófico de características físicas e químicas apresentadas nas Tabelas 1 e 2 , respectivamente.

TABELA 1 - Características granulométricas do solo utilizado no experimento.

\begin{tabular}{|c|c|c|c|}
\hline Areia* $^{*}$ & Silte* & Argila* $^{*}$ & Classe textural \\
\hline $680 \mathrm{~g} \mathrm{~kg}^{-1}$ & $40 \mathrm{~g} \mathrm{~kg}^{-1}$ & $280 \mathrm{~g} \mathrm{~kg}^{-1}$ & Argilo-arenosa** \\
\hline
\end{tabular}

*Valores obtidos através do método do densímetro; ${ }^{* \star}$ Conforme Prevedello (1996)

TABELA 2 - Características químicas do solo utilizado no experimento

\begin{tabular}{ccccccccccccc}
\hline $\mathrm{pH}$ & $\mathrm{M} . \mathrm{O}$. & $\mathrm{P}$ & $\mathrm{S}_{-} \mathrm{SO}_{4}{ }^{-2}$ & $\mathrm{~K}$ & $\mathrm{Ca}$ & $\mathrm{Mg}$ & $\mathrm{Al}$ & $\mathrm{H}+\mathrm{Al}$ & $\mathrm{SB}$ & $\mathrm{T}$ & $\mathrm{v} \%$ & $\mathrm{~m} \%$ \\
4,3 & 13 & 1 & 35,4 & 0,6 & 8 & 2 & 3 & 22,5 & 10,6 & 33,1 & 32 & 22
\end{tabular}

Laboratório de Análise de Solos - Escola Superior de Agricultura 'Luiz de Queiroz', Piracicaba - S.P. pH em $\mathrm{CaCl}_{2}$; M.O. $\left(\mathrm{g} \mathrm{dm}^{-3}\right) ; \mathrm{P}$ e S-SO ${ }_{4}^{-2}\left(\mathrm{mg} \mathrm{dm}^{-3}\right) ; \mathrm{K}, \mathrm{Ca}, \mathrm{Mg}, \mathrm{Al}, \mathrm{H}+\mathrm{Al}$, SB e T $\left(\mathrm{mmol}_{\mathrm{c}} \mathrm{dm}^{-3}\right)$.

No preenchimento das caixas colocou-se uma camada de rocha britada com aproximadamente $5 \mathrm{~cm}$ de espessura no fundo, com o intuito de evitar perda de solo e o entupimento do orifício de saída à profundidade de $60 \mathrm{~cm}$. Todo o solo utilizado foi peneirado retirando-se agregados maiores que $1 \mathrm{~cm}^{3}$.
Adotou-se delineamento em blocos casualizados, com tratamentos distribuídos em esquema fatorial $5 \times 2$, correspondentes aos tipos de fertilizantes (não adubado, efluente de biodigestor, esterco bovino, cama-de-frango, adubação mineral) e qualidades de água de irrigação (tratada e residuária) (Tabela 3 ), com três repetições. 
GALBIATTI, J. A. et al. Fertilização e qualidade...

TABELA 3 - Descrição dos tratamentos aplicados no experimento.

\begin{tabular}{lcc}
\hline \multicolumn{1}{c}{ Fertilizante } & \multicolumn{2}{c}{ Qualidade da água de irrigação } \\
\cline { 2 - 3 } & Tratada (T) & Residuária (R) \\
\hline Efluente de biodigestor & BIOT & EBR \\
Esterco bovino & EBT & CFR \\
Cama de frango & CFT & AMR \\
Mineral & AMT & NAR \\
Sem (controle) & NAT & \\
\hline
\end{tabular}

Os fertilizantes orgânicos utilizados no estudo foram obtidos junto à Faculdade de Ciências Agrárias e Veterinárias, Universidade Estadual Paulista, Jaboticabal-SP.
As características físicas, químicas e microbiológicas das águas de irrigação (tratada e residuária) utilizadas são apresentadas na Tabela 4.

TABELA 4 - Características físicas, químicas, coliformes totais (CT) e coliformes fecais (CF).

\begin{tabular}{ccc}
\hline Parâmetros & Água tratada & Água residuária \\
\hline $\mathrm{pH}$ & 7,02 & $6,6-8,8$ \\
Turbidez $(\mathrm{UNT})$ & 2,17 & $66,9-89$ \\
Condutividade $\left(\mu \mathrm{cm}^{-1}\right)$ & 123 & $96-350$ \\
Salinidade $(\% \circ)$ & 0,1 & $0,2-0,4$ \\
Sólidos. Totais Dissolvidos $\left(\mathrm{mg} \mathrm{L}^{-1}\right)$ & 58 & $45-166$ \\
Nitrato $\left(\mathrm{mg} \mathrm{L}^{-1}\right)$ & $0,05-0,09$ & $0,3-3,50$ \\
Amônia $\left(\mathrm{mg} \mathrm{L}^{-1}\right)$ & $0,04-0,11$ & $0,13-3,55$ \\
Sódio $\left(\mathrm{mg} \mathrm{L}^{-1}\right)$ & $1-16$ & 27 \\
$\mathrm{CT} \mathrm{dL}^{-1}(\mathrm{NMP})^{*}$ & & $>2.419,2$ \\
$\mathrm{CF} \mathrm{dL}$ & & $2.419,2$
\end{tabular}

Laboratório de Análises - Centro de Estudos Ambientais da UNESP, Campus de Rio Claro. * NMP = números mais prováveis de coliformes fecais e totais quantificados

As plantas foram irrigadas com água captada no Ribeirão Claro, afluente do rio Corumbataí após receber parte dos efluentes de esgoto doméstico e com água potável proveniente de estação de tratamento de Rio Claro-SP. Adotou-se lâmina equivalente a evapotranspiração média de $5 \mathrm{~mm}$ diários corrigidos pelo coeficiente de cultura $(\mathrm{Kc})$ da alface recomendados por PEREIRA e ALLEM(1997). Utilizaram-se regadores manuais com aplicação diretamente no solo.

A incorporação dos fertilizantes orgânicos foi realizada três dias antes do transplantio segundo as recomendações técnicas de adubação e calagem para o Estado de São Paulo e com base em resultados de análises químicas de solo e exigência da cultura (LOPES e GUIDOLIN, 1989; RAIJ et al., 1996), nas quantidades de $8 \mathrm{~kg} \mathrm{~m}^{-2}$ de esterco bovino, $2 \mathrm{~kg} \mathrm{~m}^{-2}$ de cama-de-frango, $32 \mathrm{~L} \mathrm{~m}^{-2}$ de efluente de biodigestor, e nos tratamentos com adubação mineral aplicaram-se $250 \mathrm{~g} \mathrm{~m}^{-2}$ de superfosfato simples, $30 \mathrm{~g} \mathrm{~m}^{-2}$ de cloreto de potássio e $10 \mathrm{~g} \mathrm{~m}^{-2}$ de nitrato de amônio. Como corretivo da acidez do solo, $300 \mathrm{~g} \mathrm{~m}^{-2}$ de calcário dolomítico em todas as parcelas. Foram realizadas incorporações de fertilizante nitrogenado em cobertura de uma única vez em cada cultivo, aplicando-se $10 \mathrm{~kg} \mathrm{ha}^{-1} \mathrm{de}$ nitrato de amônio.

Os parâmetros de crescimento e desenvolvimento avaliados foram: altura de planta, utilizando-se régua milimetrada; diâmetro do caule, com o auxílio de paquímetro digital "abbe"; produção de matéria seca e fresca total, mediante pesagem em balança digital e área foliar utilizando-se o aparelho "Plant canopy analyser - LAI - 2000", para determinação do índice de área foliar. 
Os dados foram analisados estatisticamente pelo Sistema de Análise Estatística (S.A.S.). Realizou-se análise de variância para identificação de efeito significativo e as médias foram comparadas pelo Teste de Tukey a $5 \%$ de probabilidade.

\section{RESULTADOS E DISCUSSÃO}

Não houve interação significativa entre os tipos de adubação e a qualidade da água de irrigação para quaisquer das variáveis analisadas.

Em relação ás variáveis altura de planta e diâmetro do caule, verifica-se que os tratamentos
GALBIATTI, J. A. et al. Fertilização e qualidade... apresentaram diferentes resultados nos ciclos (Figuras 1 e 2), embora sem diferenças estatísticas significativas entre si. As diferenças visuais verificadas podem ser atribuídas às variações das radiações solares e temperaturas nas condições experimentais. De uma forma geral, o EB apresentou os melhores resultados, com ou sem irrigação com água contaminada. Entretanto, os menores resultados foram registrados nos tratamentos sem o fornecimento de fertilizante para a altura e para o diâmetro nas plantas fertilizadas com CF, o que pode ser atribuído a um efeito fitotóxico, evidenciado pelo excesso de íons na solução percolada (Tabela 5).

TABELA 5 - Dados das características químicas dos fertilizantes orgânicos (FO) utilizados, cama-de-frango (CF), esterco bovino (EB) e efluente de biodigestor (BIO).

\begin{tabular}{|c|c|c|c|c|c|c|c|c|c|c|c|c|c|c|}
\hline $\mathrm{FO}$ & $\begin{array}{c}\mathrm{N} \\
\text { total }\end{array}$ & $P$ & $-\mathrm{gl}$ & $\mathrm{Ca}$ & $\mathrm{Mg}$ & $S$ & $\mathrm{Cu}$ & $\mathrm{Fe}$ & $\mathrm{Mn}$ & $-\mathrm{mg}$ & $\mathrm{Cd}$ & $\mathrm{Cr}$ & $\mathrm{Ni}$ & $\mathrm{Pb}$ \\
\hline $\begin{array}{c}\text { CF } \\
\text { EB } \\
\text { BIO }\end{array}$ & $\begin{array}{l}32,9 \\
13,1 \\
20,3\end{array}$ & $\begin{array}{l}9,3 \\
3,9 \\
5,6\end{array}$ & $\begin{array}{c}15,1 \\
19,9 \\
7,3\end{array}$ & $\begin{array}{l}24,5 \\
11,2 \\
22,1\end{array}$ & $\begin{array}{l}3,5 \\
4,9 \\
3,7\end{array}$ & $\begin{array}{l}4,1 \\
2,8 \\
4,3\end{array}$ & $\begin{array}{l}411 \\
102 \\
67.5\end{array}$ & $\begin{array}{c}565 \\
3740 \\
2555\end{array}$ & $\begin{array}{l}255 \\
430 \\
279\end{array}$ & $\begin{array}{l}256 \\
77,5 \\
235\end{array}$ & $\begin{array}{c}0 \\
0 \\
0.5\end{array}$ & $\begin{array}{c}0 \\
0,5 \\
28\end{array}$ & $\begin{array}{c}1 \\
5,5 \\
9\end{array}$ & $\begin{array}{l}0 \\
0 \\
7\end{array}$ \\
\hline
\end{tabular}

UNESP/FCAV, Jaboticabal-SP

Os resultados demonstram que os nutrientes disponíveis no EB estão prontamente assimiláveis após o processo de biodegradação, mas são facilmente lixiviados ou se tornam indisponíveis devido à imobilização microbiana, conforme reportado por CAVALCANTE et al. (1999).

aquelas irrigadas com água residuária. Entretanto, quando analisados os resultados do diâmetro do caule, registra-se situação inversa, com uma superioridade de $10,66 \%$ da água residuária; em ambos os casos sem diferença estatística significativa entre as qualidades de água aplicadas.

Plantas sob irrigação com água tratada, de uma forma geral, apresentaram altura 5,05\% maiores que

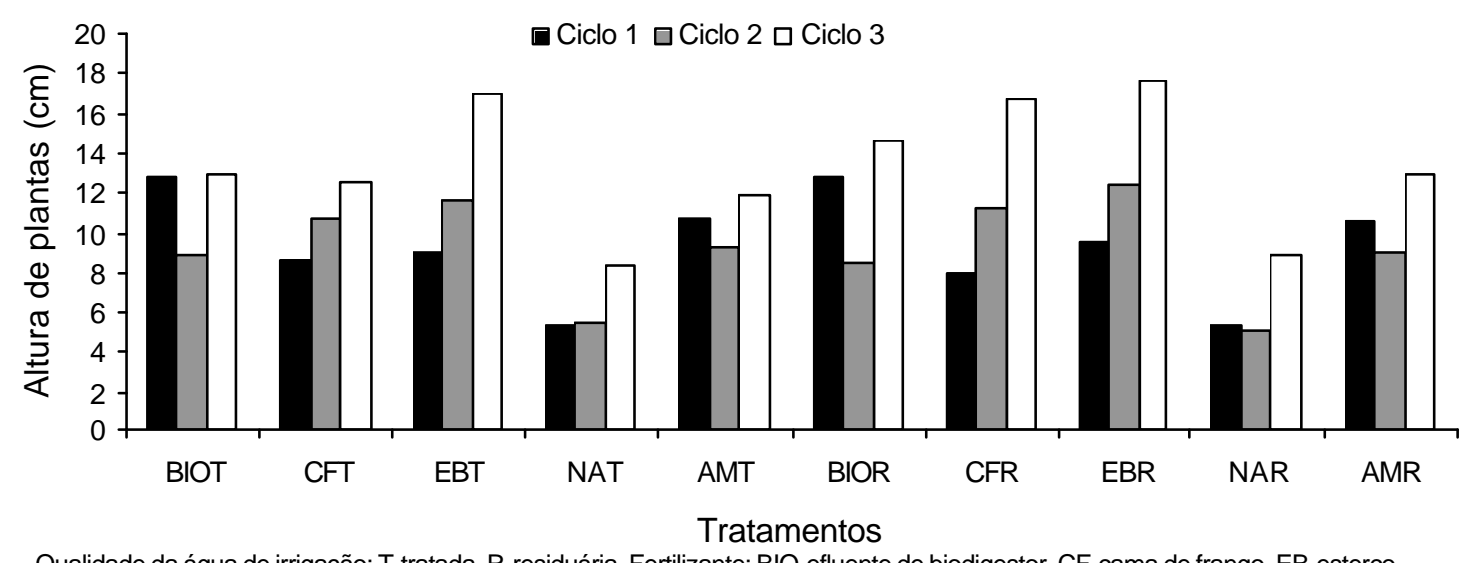

Qualidade da água de irrigação: T-tratada, R-residuária. Fertilizante: BIO-efluente de biodigestor, CF-cama de frango, EB-esterco bovino, AM-adubação mineral, NA-não adubado.

FIGURA 1 - Altura de plantas de alface em função da fertilização e qualidade da água de irrigação em três ciclos de cultivo. 
GALBIATTI, J. A. et al. Fertilização e qualidade...

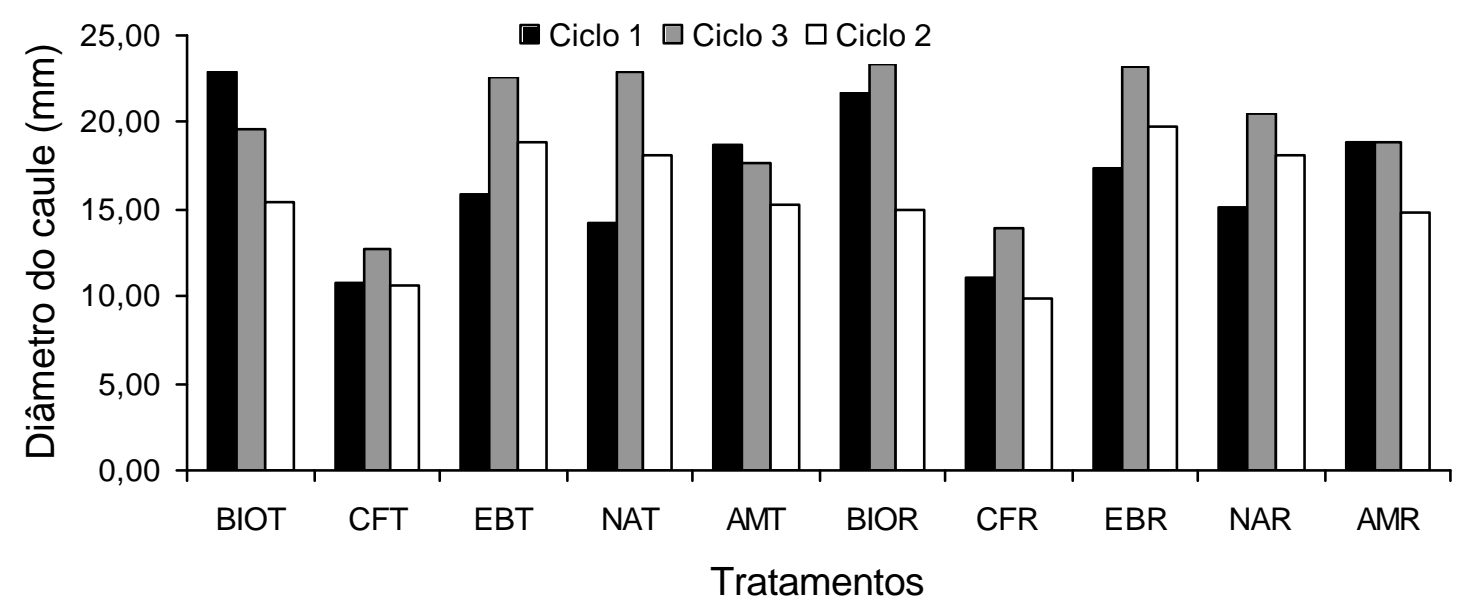

Qualidade da água de irrigação: T-tratada, R-residuária. Fertilizante: BIO-efluente de biodigestor, CFcama de frango, EB-esterco bovino, AM-adubação mineral, NA-não adubado.

FIGURA 2 - Diâmetro do caule em plantas de alface em função da fertilização e qualidade da água de irrigação em três ciclos de cultivo.

Os resultados de produção de matéria seca e fresca revelam incrementos com os ciclos de plantio (Figuras 3 e 4), para todos os tratamentos exceto a matéria seca do EBR. Observa-se que os teores de matéria seca não representam, na maioria das vezes, a produção de matéria verde pela alface, como também reportado por CRAVO (1995). Quando comparados os resultados das plantas sob a mesma fertilização não são observadas diferenças marcantes quanto à irrigação com água residuária ou tratada. ALVES e KLAR (1997) observaram que a produção da alface foi mais afetada pela lâmina de irrigação do que pelo fertilizante nitrogenado adotado para o estudo.

Comparando-se as fontes orgânicas de adubação CF, EB e BIO, observa-se que a fonte com o maior teor de $\mathrm{N}$ total (Tabela 5), nem sempre apresentou os maiores resultados de produção de matéria seca (Figura 3). Na literatura científica, alguns autores como BIE et al. (2004) associam baixas produções de matéria seca com baixos teores no fertilizante aplicado, afirmando que pode ocorrer deficiência do nutriente causando redução na fotossíntese, menor crescimento e, conseqüentemente, mais elevado teor de matéria seca total (PRIMAVESI, 1985). Esses resultados estão em concordância com os reportados por SANTOS et al. (2001) em estudo com composto orgânico no cultivo da alface, LOPES et al. (2005) estudando lodo de esgoto e PRADO et al. (2002) com aplicação de escória de siderurgia corrigida com calcário.

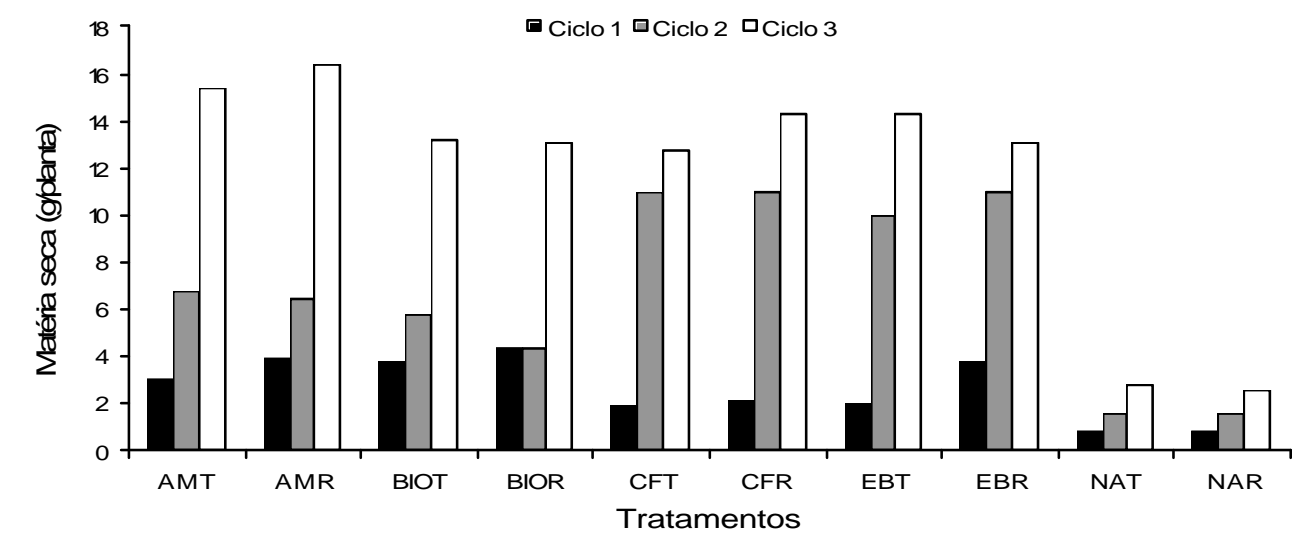

Qualidade da água de irrigação: T-tratada, R-residuária. Fertilizante: BIO-efluente de biodigestor, CF-cama de frango, EBesterco bovino, AM-adubação mineral, NA-não adubado.

FIGURA 3 - Produção de matéria seca em plantas de alface em função da fertilização e qualidade da água de irrigação em três ciclos de cultivo. 


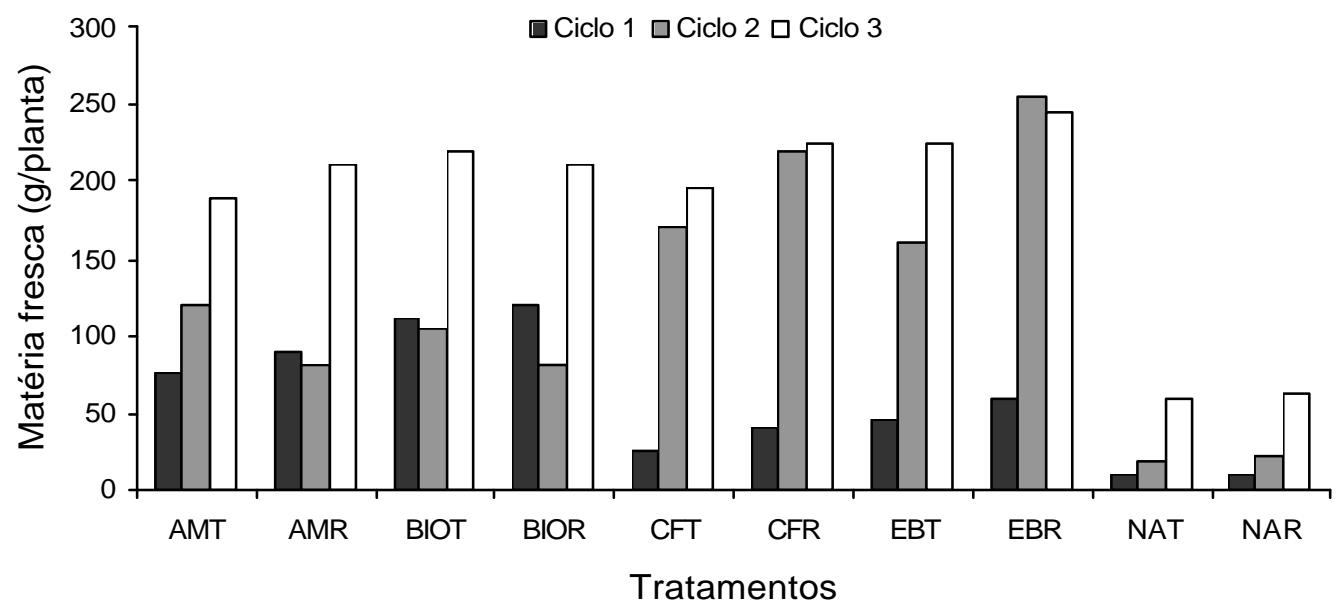

Qualidade da água de irrigação: T-tratada, R-residuária. Fertilizante: BIO-efluente de biodigestor, CF-cama de frango, EB-esterco bovino, AM-adubação mineral, NA-não adubado.

FIGURA 4 - Produçäo de materia tresca em plantas de altace em tunçäo da tertilizaçäo e qualidade da àgua de irrigação em três ciclos de cultivo.

Os menores valores foram registrados nos tratamentos sem adubação para ambas as variáveis (matérias seca e fresca), independente da qualidade da água de irrigação (Tabela 6); tratamentos semelhantes estatisticamente entre si e inferiores aos demais. Esses resultados revelam a exigência da cultura em termos nutricionais para obtenção de uma produção satisfatória em termos econômicos. Por outro lado, apesar da ausência de significância estatística, plantas irrigadas com água tratada apresentaram valores quantitativos 8,55 (matéria fresca) e 3,57\% (matéria seca) maiores que plantas irrigadas com água residuária.

TABELA 6 - Médias de produção de matéria seca (MS) e fresca (MF) e índice de área foliar (IAF) dos três ciclos de cultivo nos tratamentos estudados.

\begin{tabular}{|c|c|c|c|}
\hline \multirow{2}{*}{ Tratamento } & $\mathrm{MF}$ & \multirow[t]{2}{*}{ MS } & \multirow[t]{2}{*}{$\mathrm{IAF}$} \\
\hline & & & \\
\hline EBC & $171 \mathrm{a}$ & $9,1 \mathrm{a}$ & $4,9 a$ \\
\hline CFC & $157 \mathrm{a}$ & $9,2 \mathrm{a}$ & $4,3 a$ \\
\hline $\mathrm{BIO}$ & $142 \mathrm{a}$ & $7,6 \mathrm{a}$ & $3,5 \mathrm{a}$ \\
\hline EB & $139 a$ & $8,8 \mathrm{a}$ & $3,5 \mathrm{a}$ \\
\hline $\mathrm{BIOC}$ & $133 a$ & $7,4 \mathrm{a}$ & $3,5 \mathrm{a}$ \\
\hline $\mathrm{CF}$ & $126 \mathrm{a}$ & $8,3 \mathrm{a}$ & $2,9 a$ \\
\hline AM & $124 \mathrm{a}$ & $8,7 \mathrm{a}$ & $2,8 \mathrm{a}$ \\
\hline AMC & $121 \mathrm{a}$ & $9,1 \mathrm{a}$ & $2,8 \mathrm{a}$ \\
\hline SAC & $26 \mathrm{~b}$ & $1,6 \quad b$ & $0,4 a$ \\
\hline SA & $25 \mathrm{~b}$ & $1,7 \quad b$ & $0,2 \mathrm{a}$ \\
\hline C.V. (\%) & 17,3 & 14,8 & 16,1 \\
\hline
\end{tabular}

C.V. = coeficiente de variação; Médias seguidas de mesma letra nas colunas não diferem entre si para teste de Tukey, $\mathrm{p} \leq 0,05$.

De forma análoga à produção de matéria seca e fresca, os resultados de índice de área foliar a também foram inferiores para as plantas sem o fornecimento de nutrientes, independentemente da qualidade da água de irrigação (Figura 5). Entretanto, percebe-se uma inversão quanto aos ciclos, onde o ciclo 1 revela-se como o de maior área foliar para os tratamentos CF, CFT e EBT, o que pode ser atribuído às diferentes condições de cultivo mais favoráveis a esses tratamentos como temperatura e intensidade luminosa que, conforme AL-REDHAIMAN et al. (2003), podem interferir nesse índice.

Apesar da queda acentuada no IAF em todos os ciclos de produção para os tratamentos sem fornecimento de fertilizantes (Figura 5), não foram registradas diferenças estatísticas significativas para esse parâmetro dentre as fontes de adubação adotadas para o estudo, com ou sem o fornecimento de água com qualidade considerada inferior (Tabela 6) e, adicionalmente, plantas irrigadas com água residuaria. 
GALBIATTI, J. A. et al. Fertilização e qualidade...

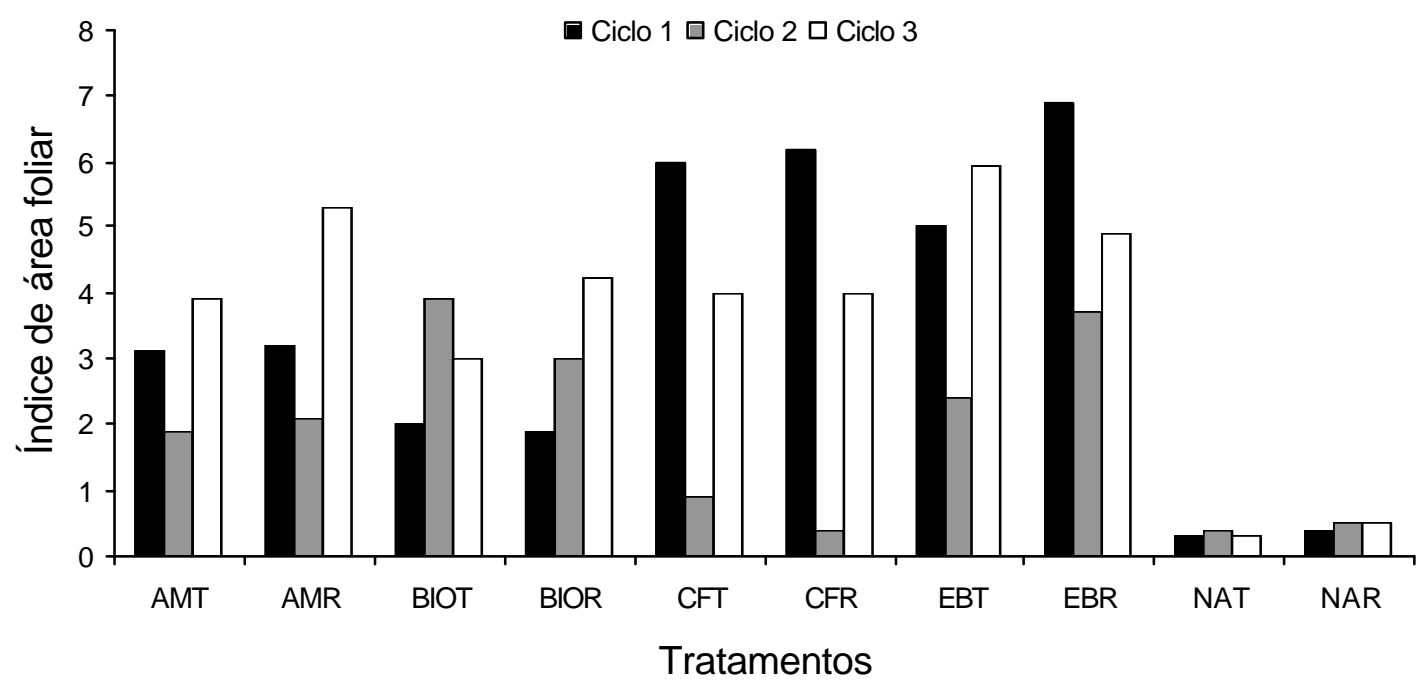

Qualidade da água de irrigação: T-tratada, R-residuária. Fertilizante: BIO-efluente de biodigestor, CF-cama de frango, EB-esterco bovino, AM-adubação mineral, NA-não adubado.

FIGURA 5 - Índice de área foliar para a alface em função da fertilização e qualidade da água de irrigação em três ciclos de cultivo.

De uma geral era esperado que os tratamentos irrigados com água tratada apresentassem resultados superiores aos demais, independentemente da fonte orgânica estudada e do ciclo de cultivo, especialmente pelas características deletérias mais expressivas que a água tratada como maior turbidez, condutividade elétrica, nitrato, sódio, amônia e coliformes (Tabela 5). Entretanto, para todas as variáveis registradas e maioria dos tratamentos, os valores foram compatíveis àqueles sob irrigação com água tratada. Apesar de discrepante, resultados semelhantes foram registrados por AL-REDHAIMAN et al. (2003) também em estudo com água de qualidade inferior e fertilização orgânica e suas implicações nas características de crescimento e desenvolvimento da alface.

\section{CONCLUSÕES}

Nas condições em que o estudo foi desenvolvido pode-se concluir que:

Não há diferença no crescimento da alface quando submetido às diferentes fontes de fertilizantes;A qualidade da água não exerce influência sobre o crescimento e desenvolvimento da alface.

\section{REFERÊNCIAS}

1. AI-REDHAIMAN, K.N.; NASSAR, I.N.; AI-SALAMAH, I.S. Effect of the municipal garbage on the growth of lettuce. Asian Journal of Plant Sciences, Faisalabad, v. 2, n. 9, p. 731-737, 2003.

2. ALVES, D.R.B.; KLAR, A.E. Efeito de adubação nitrogenada via fertirrigação e aplicação de forma convencional na produção de alface (Lactuca sativa L.) em estufa. Irriga, Botucatu, v. 2, p. 76-89, 1997.

3. BIE, Z.; ITO, T.; SHINOHARA, Y. Effects of sodium sulphate and sodium bicarbonate on the growth, gas exchange and mineral composition of lettuce. Scientia Horticulturae, Amsterdam, v. 99, p. 215-224, 2004.

4. BRASIL. Ministério do Meio Ambiente. Agenda 21. Disponível em: <http://www.mma.gov.br>. Acesso em 10 DEZ. 2005.

5. CAVALCANTE, L.F. Sais e seus problemas nos solos irrigados. Areia:UFPB, 2000.71 p.

6. CAVALCANTE, L.F.; BRASILEIRO, A.A.; SILVA, D.A.; ALVES, G.S.; CAVALCANTE, Í.H.L.; LIMA, E.M.; SANTOS, C.J.O.; SANTOS, J.B. Efeito de fontes e níveis de matéria orgânica no crescimento inicial da ateira. Anais do Curso de PósGraduação Em Manejo de Solo e Água, Areia, v. 21, p. 20-32, 1999.

7. CRAVO, M.S. Composto de lixo urbano como fonte de nutrientes e metais pesados pra alface .Piracicaba: 1995. Tese (Doutorado em Ciências) - Centro de Energia Nuclear na Agricultura, Universidade de São Paulo.

8. FILGUEIRA, F.A.R. Novo manual de agrotecnologia moderna na produção e comercialização de hortaliças . Viçosa: UFV, 2000. 402 p.

9. KIEHL, E.J. Fertilizantes orgânicos . São Paulo: Ceres, 1985. 492 p.

10. LOPES, A.S.; GUIDOLIN, J.A. Interpretação de análise de solo: conceitos e aplicações. São Paulo: ANDA, 1989. 50 p. 
GALBIATTI, J. A. et al. Fertilização e qualidade...

11. LOPES, J.C.; RIBEIRO, L.G.; ARAÚJO, M.G.; BERALDO, M.R.B.S. Produção de alface com doses de lodo de esgoto. Horticultura Brasileira, Brasília, v. 23, n. 1, p. 143-147, 2005.

12. PEREIRA, L.S.; ALLEN, R.G. Novas aproximações aos coeficientes culturais. Engenharia Agrícola, Jaboticabal, v. 16, n. 4, p. 118-143, 1997.

13. PRADO, R.M.; COUTINHO, E.L.M.; ROQUE, C.G.; VILAR, M.L.P. Avaliação da escória de siderurgia e de calcários como corretivos de acidez do solo no cultivo do alface. Pesquisa Agropecuária Brasileira, Brasília, v. 37, n. 4, p. 539546, 2002.

14. PREVEDELLO, C.L. Física do solo com problemas resolvidos . Curitiba: SAEAFS, 1996. 446 p.

15. PRIMAVESI, A. Manejo ecológico do solo: a agricultura em regiões tropicais. 8 ed. São Paulo: Nobel, 1985. 541 p.

16. RAIJ, B. van; CANTARELLA, H.; QUAGGIO, J.A.; FURLANI, A.M.C. Recomendações de adubação e calagem para o Estado de São Paulo. 2. ed. Campinas: IAC, 1996. 284 p.

17. SANTOS, R.H.S.; SILVA, F.; CASALI, V.W.D.; CONDÉ, A.R. Efeito residual da adubação com composto orgânico sobre o crescimento e produção de alface. Pesquisa Agropecuária Brasileira, Brasília, v. 36, n. 11, p. 1395-1398, 2001.

Recebido em 30/11/2006 Aceito em 12/04/2007 